\title{
PERANCANGAN APLIKASI KOMPRESI FILE VIDEO MENGGUNAKAN ALGORITMA INTERPOLATIVE CODING
}

\author{
Desvika Riyansyah
}

Program Studi Teknik Informstika STMIK Budi Darma, Medan, Indonesia

\begin{abstract}
Abstrak
Ukuran file video yang relative besar, durasi yang panjang dan memiliki kuliatas yang baik maka membutuhkan ruang penyimpanan yang besar. Dengan ukuran file video yang sangat besar, pada saat melakukan proses pemindahan bisa saja proses pemindahan gagal karena media ruang penyimpanan melebihi batasnya dan menghabiskan kuota yang sangat banyak pada saat transfer.Adapun solusi dalam permasalahan ini adalah bagaimana file video tersebut dapat dikompresi guna untuk mempercepat proses pemindahan dan penyimpanan file video serta mengehemat kuota. Dalam penelitian ini, algoritma yang digunakan adalah Interpolative Coding, , dengan mengunakan metode tersebut hasil kompresi yang berbeda - beda dari setiap nilainya, dan hasil kompresi akan menguntungkan, karena dalam melakuan pengiriman akan semakin mudah dan menghemat kuota serta menghemat ruang penyimpanan.
\end{abstract}

Kata Kunci: Kompresi File Video, Algoritma Interpolative Coding

\begin{abstract}
The size of the video files is relatively large, long duration and has a good top kulithen it requires a large storage space. With a very large video file size, at the time of the move process could be the process of moving failed because the media storage space exceeds the limit and consume very much quota at the time of transfer. The solution to this problem is how the video file can be compressed to accelerate the process of transferring and saving the video files and saving the quota. In this research, the algorithm used is Interpolative Coding, using the different compression methods-the difference of each value, and the compression results will be profitable, because the delivery will be easier and saves your quota and saves storage space.
\end{abstract}

Keywords: Video File compression, Interpolative Coding algorithm

\section{PENDAHULUAN}

Pada saat ini video merupakan hal yang sangat populer dan digemari oleh banyak kalangan. Seiring dengan perkembangan zaman yang makin maju video pun semakin banyak kegunaan dan manfaatnya bagi masyarakat. Dengan adanya video semua orang akan mendapatkan informasi lebih jelas, dapat menghibur atau menambah pengetahuan manusia dan membantu manusia berkomunikasi jarak jauh. Teknologi video saat ini juga dikembangkan dalam berbagai bidang seperti dalam bidang pedidikan hadirnya video tutorial dapat memudahkan pembelajaran atau dalam bidang jurnalis video dokumenter dapat menyajikan informasi dengan lebih akurat dan masih banyak lagi. Selain itu hadirnya teknologi video call juga memudahkan masyarakat untuk berkomunikasi jarak jauh. Video call memungkinkan manusia untuk melihat dan berbicara langsung dengan lawan bicaranya. Teknologi video sangat membantu dalam kehidupan manusia, namun file video memiliki ukuran file yang lebih besar sehingga untuk menyimpan file video dibutuhkan ruang dengan kapasitas lebih besar jika dibandingkan dengan file audio, file teks atau file gambar

Semakin besar ukuran file video maka semakin besar ruang penyimpanan yang dibutuhkan dan semakin panjang durasi dari video maka ukuran file video semakin besar. Ukuran file video mempengaruhi waktu dan kuota yang digunakan untuk proses pengiriman. Untuk itu diperlukan suatu teknik yang dapat mengurangi ukuran file video dari yang ukuran besar menjdi ukuran yang kecil tanpa mengurangi kualitas dari video tersebut.

Kompresi merupakan proses yang dilakukan untuk mengubah sebuah ukuran file yang besar menjadi ukuran yang lebih kecil dan mengurangi redudansi dari data yang terdapat dalam suatu file sehingga dapat disimpan secara efisien [1]. Kompresi file video dilakukan dengan cara memadatkan isi file sehingga ukurannya menjadi lebih kecil dengan tetap menjaga kualitas dari file video tersebut. Teknik kompresi dapat dilakukan dengan menggunakan banyak pilihan algoritma antara lain Rice Code, Goldbach, Huffman, Fibonaci Shannon Fano.

Ada beberapa faktor yang sering menjadi pertimbangan dalam memilih suatu algoritma pemanpatan data yang tepat, yaitu kecepatan dalam mengkompresi, ukuran file hasil kompresi dan ukuran kompleksitas algoritma. Data-data yang akan disimpan perlu dikompresi terlebih dahulu agar ukurannya semakin kecil. Apabila ukurannya lebih kecil dari ukuran aslinya, maka secara otomatis memori dapat menyimpan data lebih banyak lagi. salah satu dari algoritma kompresi yang bersifat lostless adalah algoritma Interpolative Coding. Algoritma Interpolative Coding merupakan cara yang tidak biasa untuk menetapkan kode dinamis ke simbol data. Ini berbeda dari metode kompresi lainnya, karena kode yang diberikannya untuk simbol individual tidak statis dan bergantung pada keseluruhan pesan dari pada pada simbol dan frekuensinya. Seluruh pesan yang di-encode harus tersedia untuk pembuat encode. Encode dilakukan dengan memindai pesan dalam urutan khusus, tidak secara linier dari awal hingga akhir, dan menugaskan codeword ke simbol saat bertemu [2].

Algoritma Interpolative Coding dapat menghitung batas bawah dan atas setiap dokumen yang mengidentifikasi kode biner tanpa menggunakan proses perulangan, sehingga waktu kompresi dapat sangat berkurang. Selain itu metode Interpolative Coding menyediakan kecepatan decoding cepat dan kompresi yang sangat baik dibandingkan dengan metode kompresi lainnya. Metode ini juga dapat digunakan untuk mendukung strategi pengindeksan diri, dan 
memberikan cara yang layak untuk membangun Information Retrieval System yang cepat dan menghemat ruang penyimpanan [3].

Interpolative Coding adalah salah satu strategi yang paling banyak digunakan karena hasil rasio kompresi yang besar. Dengan menggunakan metode Interpolative Coding ditunjukkan bahwa tidak perlu sepenuhnya mendekompresi semua node Interpolative Coding dalam pemrosesan query dan kemudian mengusulkan algoritma dekompresi keseluruhan untuk Interpolative Coding[3]. Algoritma Intervolative Coding merupakan jenis teknik komoresi lossless. Dengan menggunakan teknik kompresi lossless dimana hasil data yang di kompresi dapat dikembalikan lagi ke data aslinya dan tidak menghilangkan data sebelumnya.

\section{TEORITIS}

\subsection{Kompresi}

Kompresi adalah teknik memperkecil atau memadatkan file yang berukuran besar menjadi lebih kecil dan mengurangi kebutuhan ruang penyimpanan. Proses kompresi merupakan proses yang mengarah pada minimisasi jumlah bit untuk representasi digital seperti gambar, audio, dan video, yang menghasilkan ukuran data yang lebih kecil namun tetap menjaga kuantitas informasi dalam data tersebut [2]. Kompresi video adalah proses memperkecil atau meminimalisasi jumlah tiap bit yang merepresentasikan suatu video dengan data yang menjadi lebih kecil. Kompresi data juga diartikan sebagai teknik untuk memampatkan data agar diperoleh data dengan ukuran yang lebih kecil daripada ukuran aslinya sehingga lebih efisien dalam menyimpannya atau mempersingkat waktu pertukaran data tersebut.

\subsection{Algoritma Interpolative Coding}

Dari penjelasan maka dapat dirumuskan algoritma Interpolative Coding untuk mengompresi file teks dengan langkah-langkah sebagai berikut:

1. Baca semua karakter yang ada dalam teks untuk menghitung frekuensi kemunculan dari masing-masing karakter.

2. Masukkan nilai dari masing-masing frekuensi kemunculan karakter lalu jumlahkan kumulatif secara berurutan.

a. $\mathrm{M}=$ nilai dari masing-masing frekuensi

b. $\mathrm{L}=$ elemen atau nilai kumulatif dari $\mathrm{M}$

3. Interpolative Coding memproses data tersebut kemudian dibuatkan pohon biner untuk menentukan urutan penyelesaiannya

4. Interpolative Coding mengkompresi string dengan cara mengencode panjang dari L (elemen) yang berada ditengah.

$$
\begin{gathered}
\downarrow \\
\mathrm{L}=\mathrm{X}, \mathrm{X}, \mathrm{X}, \mathrm{X}, \mathrm{X}, \mathrm{X}, \mathrm{X}, \mathrm{X}, \mathrm{X}
\end{gathered}
$$

5. Ketika mengencode elemen yang berada ditengah, maka kita mengeksploitasi elemen awal dengan panjang elemen yang mendahuluinya yang sudah diketahui oleh decoder.

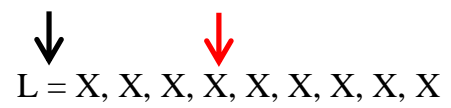

6. Perhatikan L [tengah] mendahului 4 elemen, maka:

$\mathrm{L}[$ tengah $]=$ elemen awal + jumlah elemen yang mendahuluinya

$\mathrm{L}$ [tengah] = elemen akhir - jumlah elemen yang mengikutinya

7. Kemudian kita lakukan langkah selanjutnya secara rekursif untuk mengencode semua elemen.

8. Lalu lakukan pembacaan panjang bit dengan mengunakan

$=2+($ CEILING MATH(LOG(hasil elemen yang mengikuti - hasil elemen yang mendahului +1$)$

Hasil dari penjumlahan elemen tersebut lalu diubah kebilangan biner yang nantinya akan menjadi codeword.

\section{ANALISA DAN PEMBAHASAN}

File video terkadang memiliki ukuran yang besar dibandingkan dengan ukuran file lainnya. Dengan melakukan proses kompresi terhadap file yang berukuran besar, file tersebut akan dikompresi menjadi ukuran kecil, dan akan mengurangi alokasi penyimpanan. Dalam melakukan penerapan terhadap file video harus dilakukan proses pengambilan sampel file, untuk mengambil nilai heksadesimal dari sampel file tersebut. Berikut adalah proses mengkompresi dan dekompresi file video.

Tabel 1. Informasi File MP4 Sample

\begin{tabular}{ll}
\hline Keterangan & \\
\hline Jenis File & MP4 \\
Judul & Don't Cry My Mommy
\end{tabular}




$\begin{array}{ll}\text { Ukuran } & 271.224 \mathrm{~KB} \\ \text { Durasi } & 91.56 \text { Menit }\end{array}$

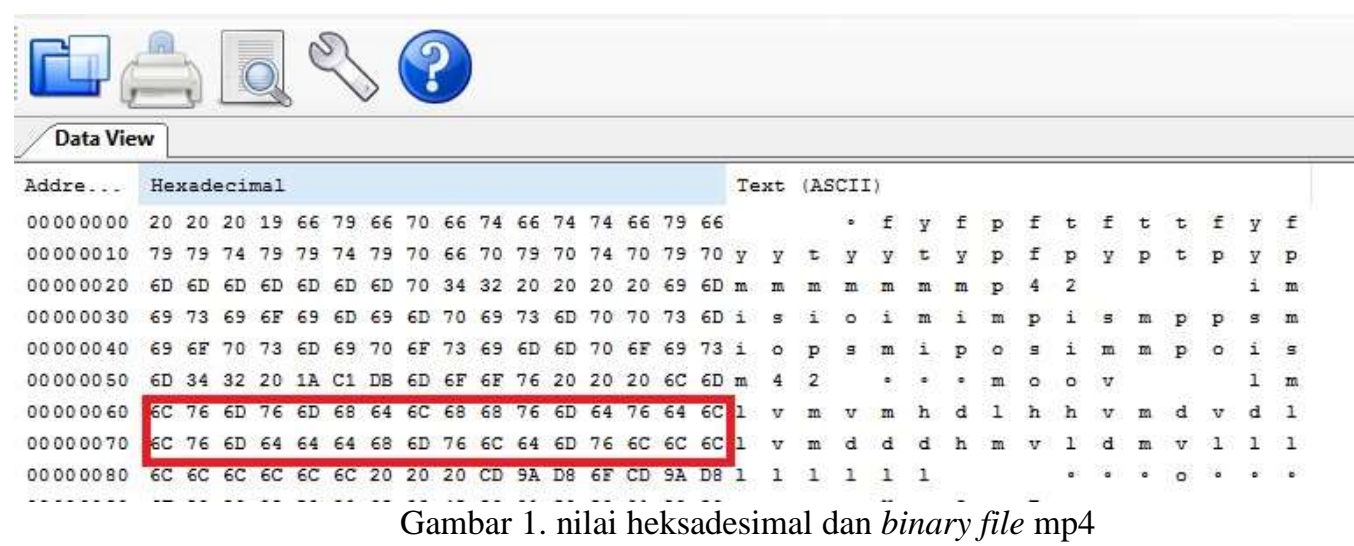

Berdasarkan pada gambar diatas didapat nilai heksadesimal file mp4. Untuk keperluan hitungan manual hanya diambil sampel nilai sebanyak 32 karakter nilai heksadesimal file mp4. Adapun bilangan heksadesimal file mp4 sampel tersebut adalah : 6C 76 6D 76 6D 6864 6C 686876 6D 647664 6C 6C 76 6D 64646468 6D 76 6C 64 6D 76 6C 6C $6 \mathrm{C}$.

Tabel 2. String yang akan dikompresi

\begin{tabular}{lllll}
\hline Nilai Hexadesimal & Nilai Biner & Bit & Freq & Bit x Freq \\
\hline $6 \mathrm{C}$ & 01101100 & 8 & 8 & 64 \\
76 & 01110110 & 8 & 7 & 56 \\
$6 \mathrm{D}$ & 01101101 & 8 & 6 & 48 \\
68 & 01101000 & 8 & 4 & 32 \\
64 & 01100100 & 8 & 7 & 56 \\
\hline Jumlah bit x frekuensi & & & 256 \\
\hline
\end{tabular}

Setelah menghitung data sebelum dikompresi, dari tabel diatas dilakukan kompresi menggunakan Algoritma Interpolative Coding, dengan mengkodekan karakter yang muncul berdasarkan urutan kemunculannya.

1. Masukkan nilai 5 frekuensi kemunculan karakter simbol pesan $\mathbf{M}=(8,7,6,4,7)=32$

2. Kemudian encode nilai dimulai dengan menghitung 5 frekuensi kemunculan karakter secara kumulatif $\mathrm{L}=$ $(8,15,21,25,32)$

3. Interpolative Coding memproses data tersebut kemudian dibuatkan pohon biner untuk menentukan urutan penyelesaiannya.

4. Dari pohon biner dapat kita ketahui bahwa urutan penyelesaiannya adalah $(21,8,15,25,32)$

5. Kemudian dilanjutkan dengan meng-encode [L] 3 yang ada ditengah. Ketika meng-encode elemen akhir maka selanjutnya mengeksploitasi elemen awal dengan panjang elemen yang mendahuluinya yang sudah diketahui oleh decoder.

6. L [3] mendahului 2 elemen

$$
\mathrm{L}=8 \underset{\downarrow}{\downarrow} 15212532
$$

L [3] mengikuti 2 elemen

Lalu encode L [3] = elemen awal + jumlah elemen yang mendahuluinya

Lalu encode L [3] = elemen akhir - jumlah elemen yang mengikutinya

$\mathrm{L}[3]=8+2=10$

$\mathrm{L}[3]=32-2=30$

Nilai Range $21-10=11$ maka nilai Binernya adalah 1011

$$
\begin{array}{r}
2+(\text { CEILING.MATH(LOG(30-10+1) }=4 \\
\qquad \mathrm{L}=815212532
\end{array}
$$

7. L [1] mendahului 0 elemen

L [1] mengikuti 2 elemen

Lalu encode L [1] = elemen awal + jumlah elemen yang mendahuluinya 
Lalu encode L [1] = elemen akhir - jumlah elemen yang mengikutinya

$\mathrm{L}[1]=8+0=8$

$\mathrm{L}[1]=21-2=19$

Nilai Range $8-8=0$ maka nilai Binernya adalah 0000

$2+($ CEILING.MATH $($ LOG $(19-8+1)=4$

$$
\mathrm{L}=815212532
$$

8. L [2] mendahului 1 elemen

L [2] mengikuti 1 elemen

Lalu encode L [2] = elemen awal + jumlah elemen yang mendahuluinya

Lalu encode L [2] = elemen akhir - jumlah elemen yang mengikutinya

$\mathrm{L}[2]=8+1=9$

L [2] $=21-1=20$

Nilai Range $15-9=6$ maka nilai Binernya adalah 0110

$2+($ CEILING.MATH $($ LOG $(20-9+1)=4$

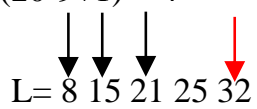

9. L [5] mendahului 2 elemen

L [5] mengikuti 0 elemen

Lalu encode L [5] = elemen awal + jumlah elemen yang mendahuluinya

Lalu encode L [5] = elemen akhir - jumlah elemen yang mengikutinya

$\mathrm{L}[5]=21+2=23$

$\mathrm{L}[5]=32-0=32$

Nilai Range $32-23=9$ maka nilai Binernya adalah 1001

$2+($ CEILING.MATH $($ LOG $(32-23+1)=4$

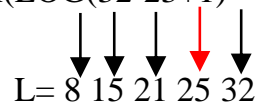

10. L [4] mendahului 1 elemen

L [4] mengikuti 1 elemen

Lalu encode L [4] = elemen awal + jumlah elemen yang mendahuluinya

Lalu encode L [4] = elemen akhir - jumlah elemen yang mengikutinya

$\mathrm{L}[4]=21+1=22$

$\mathrm{L}[4]=32-1=31$

Nilai Range $25-22=3$ maka nilai Binernya adalah 0011

$2+($ CEILING.MATH $($ LOG $(31-22+1)=4$

Tabel 3. String hasil kompresi algoritma Interpolative Coding

\begin{tabular}{llllll}
\hline Elemen & Nilai Heksa & Codeword & Bit & Freq & Bit x Freq \\
\hline L3=6C & 11 & 1011 & 4 & 8 & 32 \\
L1=76 & 0 & 0000 & 4 & 7 & 28 \\
L2=6D & 6 & 0110 & 4 & 6 & 24 \\
L5=68 & 9 & 1001 & 4 & 4 & 16 \\
L4=64 & 3 & 011 & 3 & 7 & 21 \\
\hline \multicolumn{7}{l}{ Total Bit x Frekuensi } \\
\hline
\end{tabular}

Berdasarkan tabel 3. dapat dilihat bahwa bentuk string bit dari nilai hexadesimal "6C 76 6D 76 6D $68646 \mathrm{C} 68$ 6876 6D 647664 6C 6C 76 6D 64646468 6D 76 6C 64 6D 76 6C 6C 6C," setelah dikompresi yaitu:

1011000001100000011010010111011100110010000011001100000111011101100000110110111001 01100000101101101100000101110111011

Sehingga file dengan 32 karakter mempunyai ukuran 121 bit setelah dikompresi. Namun, untuk men-decode string yang telah dikompresi, dibutuhkan padding bit dan flag bit. Padding bit adalah bit yang ditambahkan agar bit yang lain dapat dibagi 8, sedangkan flag bit adalah biner dari dari padding bit sebagai penanda yang menunjukkan tambahan bit dari padding bit.

$\begin{array}{lllll}10110000 & 01100000 & 01101001 & 01110111 & 00110010 \\ 00001100 & 11000001 & 11011101 & 10000011 & 00110110 \\ 11100101 & 10000010 & 11011011 & 00000101 & 11011101\end{array}$


Untuk men-decode string bit tersebut menjadi karakter ASCII, maka setiap string bit dibagi 8 bit, lalu dibaca dalam karakter ASCII.

\begin{tabular}{lllll}
$\frac{10110000}{\circ}$ & $\frac{01100000}{\cdot}$ & $\frac{01101001}{\mathrm{i}}$ & $\frac{01110111}{\mathrm{~W}}$ & $\frac{00110010}{2}$ \\
$\frac{00001100}{\square}$ & $\frac{11000001}{\mathrm{~A}}$ & $\frac{11011101}{\mathrm{Y}}$ & $\frac{10000011}{f}$ & $\frac{00110110}{6}$ \\
$\frac{11100101}{\mathrm{a}}$ & $\frac{10000010}{,}$ & $\frac{11011011}{\hat{\mathrm{U}}}$ & $\frac{00000101}{\square}$ & $\frac{11011101}{\hat{\mathrm{Y}}}$ \\
\hline
\end{tabular}

Kemudian string bit biner di atas diubah ke heksadesimal, maka setiap bilangan dibaca dalam karakter heksadesimal.

$\begin{array}{lllll}\frac{10110000}{\mathrm{~B} 0} & \frac{01100000}{60} & \frac{01101001}{69} & \frac{01110111}{77} & \frac{00110010}{32} \\ \frac{00001100}{\mathrm{C}} & \frac{11000001}{\mathrm{C} 1} & \frac{11011101}{\mathrm{DD}} & \frac{10000011}{83} & \frac{00110110}{36} \\ \frac{11100101}{\mathrm{E} 5} & \frac{10000010}{82} & \frac{11011011}{\mathrm{DB}} & \frac{00000101}{5} & \frac{11011101}{\mathrm{DD}} \\ \frac{10000000}{80} & \frac{00000111}{7} & & & \end{array}$

File video yang telah dikompresi dengan algoritma Interpolative Coding, tipe filenya akan diubah menjadi tipe file baru dengan ekstensi yang telah ditentukan sebagai pengenal bahwa file tersebut adalah file yang telah dikompresi dengan aplikasi kompresi yang menerapkan algoritma Interpolative Coding. Ekstensi file yang ditentukan adalah (*.ipc).

1. Compression Ratio (CR)

$$
\begin{aligned}
C R & =\frac{\text { Ukuran Data Setelah Dikompresi }}{\text { Ukuran Data Sebelum Dikompresi }} \times 100 \% \\
C R & =\frac{121}{256} \times 100 \% \\
\mathrm{CR} & =47 \%
\end{aligned}
$$

2. Redudancy

$$
\begin{aligned}
& R d=\frac{\text { file sebelum dikompresi }- \text { file setelah dikompresi }}{\text { Ukuran file sebelum dikompresi }} \times 100 \% \\
& R d=\frac{256-121}{256} \times 100 \% \\
& R d=53 \%
\end{aligned}
$$

Berikut ini adalah contoh proses dekompresi dari file hasil kompresi pada Tabel 4 :

\begin{tabular}{lll}
\multicolumn{3}{l}{ Tabel 4. nilai heksa dan biner setelah di kompresi } \\
\cline { 1 - 3 } Urutan Nilai & Nilai Hexa & Nilai Biner \\
\hline 1 & B0 & 10110000 \\
2 & 60 & 01100000 \\
3 & 69 & 01101001 \\
4 & 77 & 01110111 \\
5 & 32 & 00110010 \\
8 & DD & 11011101 \\
9 & 83 & 10000011 \\
10 & 36 & 00110110 \\
11 & E5 & 11100101 \\
12 & 82 & 10000010 \\
13 & DB & 11011011 \\
14 & 5 & 00000101 \\
15 & DD & 11011101 \\
16 & 80 & 10000000 \\
17 & 7 & 00000111 \\
\hline
\end{tabular}

Berdasarkan pada tabel di atas maka diambil keseluruhan nilai biner dan digabungkan seperti berikut ini :

1. Tahap Pertama

Proses pertama dekompresi adalah menganalisa keseluruhaan bit hasil dari kompresi sebelumnya adapun bit keseluruhan hasil kompresi dapat dilihat pada table 4. 
Didapatkan nilai 8 bit terakhir sebagai berikut, 00000111 dalam nilai hexadesimal adalah merupakan nilai 7. Nilai 7 tersebut menandakan bahwa hasil kompresi sebelumnya habis dibagi 8 sehingga ada penambahan padding dan flag bits. Selanjutnya hapus padding dan flag bit dari nilai keseluruhan bit sehingga menjadi seperti di bawah ini: 101100000110000001101001011101110011001000001100110000011101110110000011011011 100101100000101101101100000101110111011

2. Pengecekan Bit

Selanjutnya adalah melakukan pengecekan nilai bit, dari bit pertama dengan Interpolative Coding pada tabel 4 di atas.

Tabel 5. Dekompresi Nilai Heksa Video sampel

\begin{tabular}{|c|c|c|c|}
\hline Urutan Nilai & Interpolative Coding & Nilai Hexa & Biner \\
\hline 1 & 1011 & $6 \mathrm{C}$ & 01101100 \\
\hline 2 & 0000 & 76 & 01110110 \\
\hline 3 & 0110 & $6 \mathrm{D}$ & 01101101 \\
\hline 4 & 0000 & 76 & 01110110 \\
\hline 5 & 0110 & $6 \mathrm{D}$ & 01101101 \\
\hline 6 & 1001 & 68 & 01101000 \\
\hline 7 & 011 & 64 & 01100100 \\
\hline 8 & 1011 & $6 \mathrm{C}$ & 01101100 \\
\hline 9 & 1001 & 68 & 01101000 \\
\hline 10 & 1001 & 68 & 01101000 \\
\hline 11 & 0000 & 76 & 01110110 \\
\hline 12 & 0110 & $6 \mathrm{D}$ & 01101101 \\
\hline 13 & 011 & 64 & 01100100 \\
\hline 14 & 0000 & 76 & 01110110 \\
\hline 15 & 011 & 64 & 01100100 \\
\hline 16 & 1011 & $6 \mathrm{C}$ & 01101100 \\
\hline 17 & 1011 & $6 \mathrm{C}$ & 01101100 \\
\hline 18 & 0000 & 76 & 01110110 \\
\hline 19 & 0110 & $6 \mathrm{D}$ & 01101101 \\
\hline 20 & 011 & 64 & 01100100 \\
\hline 21 & 011 & 64 & 01100100 \\
\hline 22 & 011 & 64 & 01100100 \\
\hline 23 & 1001 & 68 & 01101000 \\
\hline 24 & 0110 & $6 \mathrm{D}$ & 01101101 \\
\hline 25 & 0000 & 76 & 01110110 \\
\hline 26 & 1011 & $6 C$ & 01101100 \\
\hline 27 & 011 & 64 & 01100100 \\
\hline 28 & 0110 & $6 \mathrm{D}$ & 01101101 \\
\hline 29 & 0000 & 76 & 01110110 \\
\hline 30 & 1011 & $6 \mathrm{C}$ & 01101100 \\
\hline 31 & 1011 & $6 \mathrm{C}$ & 01101100 \\
\hline 32 & 1011 & $6 \mathrm{C}$ & 01101100 \\
\hline
\end{tabular}

\section{KESIMPULAN}

Berdasarkan dari penelitian yang telah dilakukan, maka hasil akhir dari penelitian tersebut dapat diambil beberapa kesimpulan dari pembahasan sebelumnya. Adapun kesimpulan tersebut sebagai berikut:

1. Berdasarkan prosedur kompresi dengan menggunakan algoritma Interpolative coding telah berhasil melakukan proses kompresi file video berekstensi *.mp4 sehingga proses kompresi dapat berjalan sesuai dengan teknik kompresi.

2. Berdasarkan penerapan algoritma Interpolative coding telah membuktikan bahwa suatu file video yang memiliki ukuran besar dapat dikompres menjadi ukuran yang lebih kecil. Berdasarkan dari hasil pengujian terhadap sistem bahwa ukuran file video lebih kecil setelah dilakukan kompresi dengan rasio $47 \%$.

3. Kompresi file video dapat dirancang dan dibangun dengan menggunakan aplikasi Microsoft Visual Basic Studio 2008 dengan menerapkan algoritma Interpolative coding.

\section{REFERENCES}

[1] D. Salomon and G. Motta, "Handbook of Data Compression Fifth Edition." Springer-Verlag London Limited, London, 2010.

[2] D. Putra, Pengolahan Citra Digital. Yogyakarta: C.V Andi Offset, 2010.

[3] J. Wang, H. Wang, and D. Hutchison, Systems Engineering - WISE 2016. 2016. 